OPEN ACCESS

Edited by:

Edvaldo Antonio Ribeiro Rosa, The Pontifical Catholic University of

Paraná, Brazil

Reviewed by:

Dmitri Debabov

NovaBay Pharmaceuticals, USA

Siddharth Kaushal Tripathi,

University of Mississippi, USA

${ }^{*}$ Correspondence:

Stawomir Milewski,

Department of Pharmaceutical

Technology and Biochemistry, Gdańsk

University of Technology, 11/12

Narutowicza St., 80-233 Gdańsk,

Poland

slamilew@pg.gda.pl

${ }^{\dagger}$ Present Address:

Marie Kodedová,

Department of Membrane Transport,

Institute of Physiology, Academy of

Sciences of the Czech Republic, v.v.i.,

Prague, Czech Republic:

Rajendra Prasad,

Amity Institute of Integrative Sciences and Health and Amity Institute of

Biotechnology, Amity University

Haryana, Gurgaon, India

Specialty section

This article was submitted to Antimicrobials, Resistance and Chemotherapy

a section of the journal

Frontiers in Microbiology

Received: 05 June 2015

Accepted: 17 July 2015

Published: 05 August 2015

Citation:

Łạcka I, Konieczny MT, Bułakowska A, Kodedová M, Gašková D, Maurya IK, Prasad R and Milewski S (2015)

Chemosensitization of multidrug resistant Candida albicans by the oxathiolone fused chalcone

derivatives. Front. Microbiol. 6:783. doi: 10.3389/fmicb.2015.00783

\section{Chemosensitization of multidrug resistant Candida albicans by the oxathiolone fused chalcone derivatives}

\author{
Izabela Łącka ${ }^{1}$, Marek T. Konieczny ${ }^{2}$, Anita Bułakowska', Marie Kodedová ${ }^{\dagger}$, \\ Dana Gašková ${ }^{3}$, Indresh K. Maurya ${ }^{4}$, Rajendra Prasad ${ }^{4+}$ and Sławomir Milewski ${ }^{1 *}$ \\ ${ }^{1}$ Department of Pharmaceutical Technology and Biochemistry, Gdańsk University of Technology, Gdańsk, Poland, \\ ${ }^{2}$ Department of Organic Chemistry, Medical University of Gdańsk, Gdańsk, Poland, ${ }^{3}$ Faculty of Mathematics and Physics, \\ Charles University in Prague, Prague, Czech Republic, ${ }^{4}$ Membrane Biology Laboratory, School of Life Sciences, Jawaharlal \\ Nehru University, New Delhi, India
}

Three structurally related oxathiolone fused chalcone derivatives appeared effective chemosensitizers, able to restore in part sensitivity to fluconazole of multidrug-resistant C. albicans strains. Compound $\mathbf{2 1}$ effectively chemosensitized cells resistant due to the overexpression of the MDR1 gene, compound $\mathbf{6}$ reduced resistance of cells overexpressing the $\mathrm{ABC}$-type drug transporters $C D R 1 / C D R 2$ and derivative $\mathbf{1 8}$ partially reversed fluconazole resistance mediated by both types of yeast drug efflux pumps. The observed effect of sensitization of resistant strains of Candida albicans to fluconazole activity in the presence of active compounds most likely resulted from inhibition of the pump-mediated efflux, as was revealed by the results of studies involving the fluorescent probes, Nile Red, Rhodamine $6 \mathrm{G}$ and $\mathrm{diS}_{-} \mathrm{C}_{3}(3)$.

Keywords: multidrug resistance, chalcones, antifungals, chemosensitization, Candida albicans

\section{Introduction}

Opportunistic fungal infections in immunocompromised hosts have become an important clinical problem, with Candida species remaining one of the leading causes of hospital-acquired bloodstream infections. The attributable frequency of deaths from candidemia remains close to $40 \%$ and Candida albicans comprises nearly half of the isolated fungal pathogens (Pfaller and Diekema, 2007). The main factors determining high mortality from candidal infections are: a limited repertoire of clinically used antimycotics and an emerging appearance of drug resistance, including its multidrug form (Sanglard and Odds, 2002; Pfaller, 2012; Srinivasan et al., 2012). Among molecular mechanisms underlying multidrug resistance (MDR), the most important is an overproduction of membrane proteins belonging to the ATP-binding cassette $(\mathrm{ABC})$ transporters or the major facilitator superfamily (MFS). A number of efflux pumps have been identified in fungi, including Cdr1p, Cdr2p, Mdr1p, and Flu1p in C. albicans (Prasad et al., 2002; Prasad and Goffeau, 2012). In view of these facts, the search for new antimycotics active against MDR fungi and/or chemosensitizers, i.e., compounds able to render MDR strains sensitive to clinically used antifungals, is an urgent need. Chemosensitization has been postulated as one of the ways of overcoming fungal resistance to the most popular triazole antifungals, including fluconazole (FLC). Reported examples of compounds effectively chemosensitizing FLC-resistant human pathogenic 
fungi include Cdr1p/Cdr2p-specific curcumin (Sharma et al., 2009), ibuprofen (Ricardo et al., 2009), or cyclosporine (Marchetti et al., 2000), inhibitors of MFS-type drug transporters, like cerulenin analogs (Diwischek et al., 2009) or synthetic heterocycles containing a cyclobutenedione core (Keniya et al., 2015) and clorgyline, targeting both types of fungal drug efflux pumps (Holmes et al., 2012).

Chalcones, compounds constituting a subclass of flavonoids, exhibit a number of biological effects, including antimicrobial activity (Dimmock et al., 1999; Nowakowska, 2007). Antifungal properties of some chalcones were demonstrated and it was suggested that the observed activity might be related to the inhibition of biosynthesis of cell wall components, $\beta(1 \rightarrow 3)$ glucan and chitin (López et al., 2001). It was also shown that some of the chalcone derivatives inhibited drug extrusion by the yeast drug transporters of the ABC type (Conseil et al., 2000; Wink et al., 2012).

We reported previously that a synthetic oxathiolone fused chalcone derivative AMG-148 exhibited in antifungal activity (Łącka et al., 2011). In the present communication, results of our studies on structural analogs of AMG-148, concerning especially their chemosensitizing effect on MDR yeast cells, are described.

\section{Materials and Methods}

\section{Compounds and Reagents}

The oxathiolone fused chalcone derivatives were synthesized as described (Konieczny et al., 2007a,b,c). Fluconazole was kindly provided by Pliva Krakow (Cracow, Poland). All other chemicals were from Sigma-Aldrich, St. Louis, MO.

\section{Strains and Culture Conditions}

The reference strain used in this study was Candida albicans ATCC 10231. Non-reference strains are listed in Table 1. C. albicans F2, F5, B3, B4, Gu4, and Gu5 clinical isolates (Franz et al., 1998, 1999) were kindly provided by J. Morschhäuser, Würzburg, Germany, while DSY2039 and DSY750 by D. Sanglard, Lausanne, Switzerland. S. cerevisiae $\mathrm{AD}^{-8 \mathrm{u}^{-}}$and US50-18C mutants AD1-3, AD12, AD13, and AD23 were kindly provided by A. Goffeau, Louvain-la-Neuve, Belgium. The AD-derived strains ADCDR1, ADCDR2, and ADMDR1 were constructed by the previously described methods (Gupta et al., 1998; Prasad et al., 1998; Smriti et al., 2002). Strains were grown at $30^{\circ} \mathrm{C}$ in Sabouraud medium ( $2 \%$ glucose, $1 \%$ yeast extract, and $2 \%$ bactopeptone) and stored on Sabouraud plates containing $2 \%$ agar.

\section{Susceptibility Testing Procedures}

MIC values of tested compounds were determined in RPMI-1640 medium by the slightly modified serial dilution microtiter plate method recommended by CLSI (Clinical Laboratory Standards Institute, 2008). Turbidity in individual wells was measured with a microplate reader (Victor ${ }^{3} \mathrm{~V}$, Perkin Elmer). The MIC was defined as the lowest drug concentration at which at least $80 \%$
TABLE 1 | Non-reference yeast strains used in this study.

\begin{tabular}{|c|c|c|}
\hline Strains & Description & $\begin{array}{l}\text { Source/ } \\
\text { references }\end{array}$ \\
\hline \multicolumn{3}{|c|}{ SACCHAROMYCES CEREVISIAE } \\
\hline US50-18C & MAT $\alpha, P D R 1-3$, ura3, his1 (parent strain) & Balzi et al., 1987 \\
\hline AD1-8u ${ }^{-}$ & 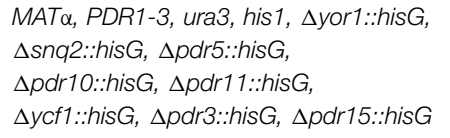 & Decottignies et al., 1998 \\
\hline ADCDR1 & AD1-8u ${ }^{-}$transformed with $\mathrm{CaCDR1}$ & Smriti et al., 2002 \\
\hline ADCDR2 & AD1-8 $\mathrm{u}^{-}$transformed with $\mathrm{CaCDR2}$ & Smriti et al., 2002 \\
\hline ADMDR1 & AD1-8 $\mathrm{u}^{-}$transformed with CaMDR1 & Gupta et al., 1998 \\
\hline AD1-3 & 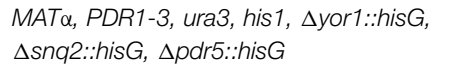 & Decottignies et al., 1998 \\
\hline AD12 & 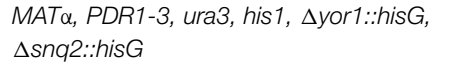 & Decottignies et al., 1998 \\
\hline AD13 & 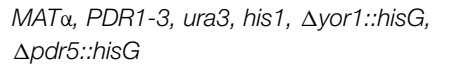 & Decottignies et al., 1998 \\
\hline AD23 & $\begin{array}{l}\text { MATa, PDR1-3, ura3, his1, } \\
\Delta s n q 2:: h i s G, \Delta p d r 5:: h i s G\end{array}$ & Decottignies et al., 1998 \\
\hline \multicolumn{3}{|c|}{ CANDIDA ALBICANS CLINICAL ISOLATES } \\
\hline Gu4 & Fluconazole sensitive & Franz et al., 1998 \\
\hline Gu5 & $\begin{array}{l}\text { Fluconazole-resistant due to the } \\
\text { overexpression of CDR1 and CDR2 }\end{array}$ & Franz et al., 1998 \\
\hline $\mathrm{F} 2$ & Fluconazole sensitive & Franz et al., 1999 \\
\hline F5 & $\begin{array}{l}\text { Fluconazole-resistant due to the } \\
\text { overexpression of CaMDR1 and ERG11 }\end{array}$ & Franz et al., 1999 \\
\hline B3 & Fluconazole sensitive & Franz et al., 1998 \\
\hline B4 & $\begin{array}{l}\text { Fluconazole-resistant due to the } \\
\text { overexpression of CaMDR1 }\end{array}$ & Franz et al., 1998 \\
\hline DSY2039 & Fluconazole sensitive & D.S. ${ }^{a}$ \\
\hline DSY750 & $\begin{array}{l}\text { Fluconazole-resistant due to the } \\
\text { overexpression of CaMDR1 }\end{array}$ & D.S. \\
\hline
\end{tabular}

${ }^{a}$ strains provided by Dominique Sanglard, Lausanne, Switzerland.

decrease in turbidity, in comparison to the drug-free control, was observed.

The same conditions were applied for quantification of an antifungal effect of chalcones in combination with Fluconazole (FLC), using the checkerboard microdilution assay. The final concentrations of chalcones ranged from 2 to $64 \mu \mathrm{g} / \mathrm{mL}$ for all chalcones but 11, for which the concentration range was 0.0625 to $2 \mu \mathrm{g} / \mathrm{mL}$. FLC was tested in the $0.03125-8 \mu \mathrm{g} / \mathrm{mL}$ range. The data obtained by the checkerboard microdilution assays were analyzed using the model-fractional inhibitory concentration (FIC) index method based on the Loewe theory. The FIC index is defined as the sum of the MIC of each drug when used in combination divided by the MIC of the drug used alone. Synergy and antagonism were defined by FIC indexes of $\leq 0.5$ and $>4$, respectively. A FIC index value $>0.5$ but $\leq 4$ was considered indifferent (Odds, 2003).

\section{ATPase Activity Assay}

The ATPase activity of the plasma membrane fractions was measured in terms of oligomycin-sensitive release of inorganic phosphate, as described previously (Smriti et al., 2002), either alone or in the presence of compounds tested. 


\section{Quantification of Energy-dependent Rhodamine 6G Efflux}

Preparation of yeast cells was performed as described previously (Sharma et al., 2009). Rhodamine 6G (R6G) solution was added to $1 \mathrm{ml}$ aliquots of $2 \%$ cell suspension in PBS (to get the $10 \mu \mathrm{M}$ final concentration of R6G) along with the compound tested and the mixtures were incubated for $1 \mathrm{~h}$ at $30^{\circ} \mathrm{C}$. The cells were washed twice with PBS and re-energized by re-suspending them in $1 \mathrm{ml}$ of PBS containing $2 \%$ glucose and incubated at $30^{\circ} \mathrm{C}$ for $30 \mathrm{~min}$. After incubation, the samples were centrifuged at $9000 \times$ $\mathrm{g}$ for $2 \mathrm{~min}$ and absorption of the supernatant was measured at $527 \mathrm{~nm}$.

\section{Nile Red Accumulation Assay}

The accumulation of Nile Red (NR) was determined by modification of the method described elsewhere (Ivnitski-Steele et al., 2009) and measured with a FACSort flow cytometer (Becton-Dickinson Immunocytometry Systems, San Jose, CA). Exponential phase yeast cells were collected, washed $3 \times$ with water and suspended in PBS, pH 7.4, containing $2 \%$ glucose to the final cell density $2 \%(\mathrm{w} / \mathrm{v})$. The NR solution was added to $1 \mathrm{ml}$ portions of the cell suspension in PBS/glucose to get the $7 \mu \mathrm{M}$ final concentration of $\mathrm{NR}$, along with the compound tested. After $30 \mathrm{~min}$ incubation at $30^{\circ} \mathrm{C}$, the samples were excited with a 488 $\mathrm{nm}$ laser and PE-Texas Red filter was used to detect NR-derived fluorescence. The mean fluorescence intensity was calculated using the histogram stat program. Analysis was performed with the CellQuest software (Becton-Dickinson Immunocytometry Systems).

\section{DiS- $\mathbf{C}_{3}(3)$ Accumulation Assay}

Fluorescence measurement of $\mathrm{diS}-\mathrm{C}_{3}(3)$ accumulation in cells was performed using the procedure described previously (Hendrych et al., 2009). Briefly, the fluorescent probe diS- $\mathrm{C}_{3}(3)$ (final concentration $2 \times 10^{-8} \mathrm{M}$ ) was added to the cell suspension 10 min after compounds tested and fluorescence emission spectra of the cell suspensions were measured $\left(\lambda_{\mathrm{ex}}=531 \mathrm{~nm}\right)$ at the time of staining. In each experiment, the CD cocktail $(5 \mu \mathrm{M}$ CCCP plus $10 \mu \mathrm{M}$ DM-11) was added, usually after $40 \mathrm{~min}$ of staining.

\section{Transmission Electron Microscopy}

C. albicans cells from the overnight cultures were harvested, washed and suspended in Sabouraud medium to the final cell density of $\approx 10^{6} \mathrm{cfu} / \mathrm{mL}$. The compounds tested were added and cultures were incubated for $9 \mathrm{~h}$ at $30^{\circ} \mathrm{C}$. For ultrastructural studies, the cells were fixed with $2 \%$ glutaraldehyde in $0.1 \%$ phosphate buffer for $3 \mathrm{~h}$ at $25^{\circ} \mathrm{C}$, washed with $0.1 \mathrm{M}$ phosphate buffer ( $\mathrm{pH} 7.2$ ) and post-fixed with $1 \% \mathrm{OsO}_{4}$ in $0.1 \mathrm{M}$ phosphate buffer for $1 \mathrm{~h}$ at $4^{\circ} \mathrm{C}$. Samples were dehydrated with graded acetone, cleared with toluene, infiltered consequently with toluene and araldite mixture at room temperature and pure araldite at $50^{\circ} \mathrm{C}$ and finally embedded in an Eppendorff tube with pure araldite mixture at $60^{\circ} \mathrm{C}$. Semithin and ultrathin section cutting was done with ultramicrotome (Ultramicotome Lecia EM UC6). Sections were taken on the $3.05 \mathrm{~mm}$ diameter, 200 mesh copper grid, stained with uranyl acetate.

\section{Results}

\section{Growth Inhibitory Effect of Chalcone Derivatives}

In the previous study, AMG-148, an oxathiolone fused chalcone derivative, was found to exhibit in vitro antifungal activity against several strains of human pathogenic yeasts, with MIC values within the range of $1-16 \mu \mathrm{g} / \mathrm{mL}$ and a fungicidal effect was observed at concentrations 4-32-fold higher than the MICs (Łącka et al., 2011). In this work, a growth inhibitory effect of AMG-148 (here compound 11) was compared to that of its 26 structural analogs, using the serial dilution microtiter plate method employing C. albicans ATCC 10231 as a reference microorganism. Results presented in Table 2 indicate that all compounds but 11 exhibited poor anticandidal activity, with MICs in the $64->256 \mu \mathrm{g} / \mathrm{mL}$ range. MIC of the known antifungal drug FLC in this assay was $2 \mu \mathrm{g} / \mathrm{mL}$.

\section{Combined Antifungal Effect of Chalcone Derivatives and Fluconazole}

Antifungal effect of 11 chalcone derivatives with MIC values $\leq$ $64 \mu \mathrm{g} / \mathrm{mL}$ (Table 2) in combination with FLC was quantified using the checkerboard serial dilution assay. The only case of a slight synergistic effect was noted for combination of FLC with compound 11, where a FIC index $=0.22$ was determined. For combinations of all the other 10 chalcones tested with FLC, the FIC indexes were in the 0.92-1.36 range, thus indicating neither synergy nor antagonism.

\section{Modulation of Multidrug Resistance}

Some natural flavonoids and their synthetic derivatives were reported to be effective modulators of microbial multidrug resistance (Ivanova et al., 2008; Liu et al., 2008; Sharma et al., 2010). To check whether chalcones tested in this work were able to restore the antifungal potency of FLC against FLC-resistant human pathogenic yeasts, an in vitro assay was performed employing C. albicans clinical isolates resistant to fluconazole, due to the FLC-induced overexpression of genes encoding multidrug efflux pumps. The Gu5 and B4 isolates are FLCresistant, due to the documented overexpression of $C D R 1$ and/or $C D R 2$ in the former and MDR1 in the latter. Their FLCsensitive counterparts, Gu4 and B3, respectively, exhibit a basal expression of these resistance genes. The antifungal activity of FLC against Candida isolates was determined in the presence of a fixed concentration of each chalcone. All compounds were tested at concentrations that did not interfere with fungal growth (< $1 / 2 \mathrm{MIC} ; 0.5 \mu \mathrm{g} / \mathrm{mL}$ for 11 and $25 \mu \mathrm{g} / \mathrm{mL}$ for the other compounds). Sixteen out of twenty seven chalcones did not show any effect but the remaining 11 were able to decrease the $\mathrm{MIC}_{\mathrm{FLC}}$ value of at least one of the FLC-resistant isolates (Table 3). Eight derivatives demonstrated ability to enhance sensitivity of C. albicans B4 to FLC. This effect was significant in the case of compounds 11, 18, and 21. Seven compounds were able to enhance sensitivity of $C$. albicans Gu5 to FLC, however this change was significant only for compounds 6 and 18. The chemosensitizing efficiency of compounds $\mathbf{6 , 1 8}$, and 21 is thus comparable to that of the known chemosensitizers of fungal drug efflux pumps, verapamil and trifuoperazine. On the other hand, 
TABLE 2 | Fungistatic activity of oxathiolone-fused chalcones.

\begin{tabular}{|c|c|c|c|c|c|c|}
\hline Compound & \multicolumn{5}{|c|}{ Structure } & $\begin{array}{c}\text { MIC }^{a}\left(\mu \mathrm{g} \mathrm{mL}^{-1}\right) \\
\text { C. albicans } \\
\text { ATCC } 10231\end{array}$ \\
\hline
\end{tabular}

Type 1

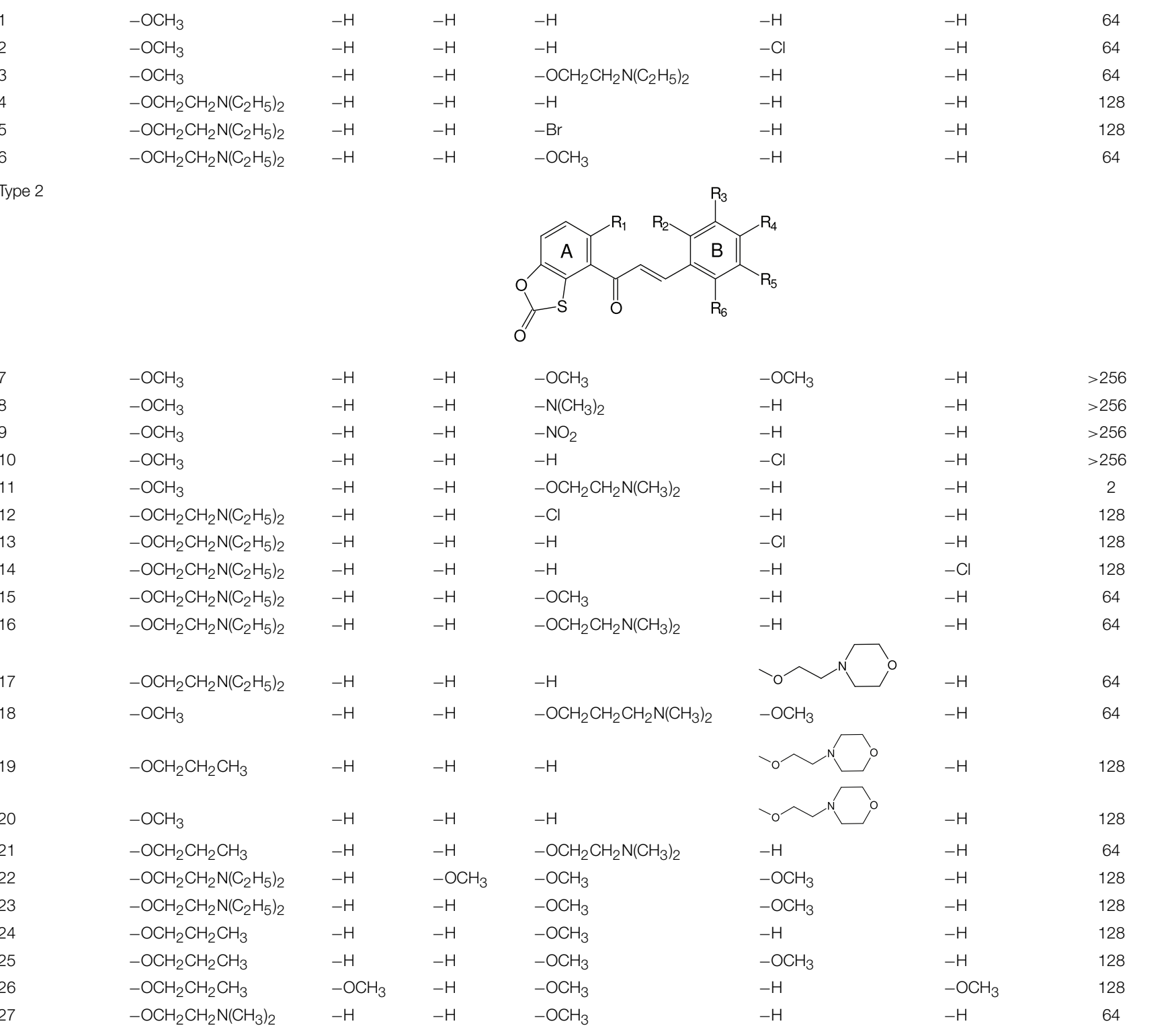

${ }^{a}$ MICs were determined in RPMI-1640 buffered medium, as described in Materials and Methods.

the observed substantial reduction of $\mathrm{MIC}_{\mathrm{FLC}}$ of the $\mathrm{B} 4$ strain in presence of 11 may result from chemosensitization, but at least in part could be also attributed to the observed synergism between FLC and 11 as antifungals.
Several lower concentrations of compounds listed in Table 3 were examined in order to find the lowest concentrations at which the FLC-sensitizing effect was observed. In the case of CDR1/CDR2-overexpressing C. albicans Gu5, a two-fold 
TABLE 3 | Influence of chalcones on MIC $_{\mathrm{FLC}}$ values determined for Candida albicans clinical isolates.

\begin{tabular}{lcccc}
\hline Compound & \multicolumn{4}{c}{ MIC of FLC $(\boldsymbol{\mu} \mathbf{g} / \mathbf{m L})^{\mathbf{a}}$} \\
\cline { 2 - 5 } & B3 & B4 & Gu4 & Gu5 \\
\hline- & 1 & 16 & 4 & 256 \\
5 & 1 & 4 & 4 & 256 \\
$\mathbf{6}$ & 1 & 16 & 4 & $\mathbf{3 2}$ \\
$\mathbf{1 1}$ & 0.5 & $\mathbf{1}$ & 2 & 128 \\
15 & 1 & 8 & 4 & 64 \\
$\mathbf{1 8}$ & 1 & $\mathbf{2}$ & 4 & $\mathbf{3 2}$ \\
19 & 1 & 8 & 4 & 256 \\
20 & 1 & 16 & 4 & 128 \\
$\mathbf{2 1}$ & 1 & $\mathbf{2}$ & 4 & 64 \\
22 & 1 & 16 & 4 & 128 \\
23 & 1 & 8 & 4 & 128 \\
25 & 1 & 8 & 4 & 128 \\
VP) & 1 & $\mathbf{0 . 5}$ & 4 & 64 \\
TFPb & 1 & $\mathbf{1}$ & 4 & 128 \\
\hline
\end{tabular}

${ }^{a}$ MIC values for FLC were determined by the serial dilution method as described Materials and Methods, in the presence of a fixed concentration of a compound tested $(0.5 \mu \mathrm{g} / \mathrm{mL}$ for 11 and $25 \mu \mathrm{g} / \mathrm{mL}$ for the other compounds).

${ }^{b}$ Verapamil $(50 \mu \mathrm{g} / \mathrm{mL})$ and trifluoroperazine $(20 \mu \mathrm{g} / \mathrm{mL})$ were used as positive controls. Cases of significant (>4-fold) MIC $F L C$ reduction by a given compound are highlighted in bold.

TABLE 4 | Activity of compounds 6, 18, 21 and fluconazole against MDR C. albicans clinical isolates and their drug-sensitive counterparts.

\begin{tabular}{lcccc}
\hline Strain & \multicolumn{3}{c}{ MIC/IC $_{\mathbf{5 0}}^{\mathbf{a}}(\boldsymbol{\mu} \mathbf{g} / \mathbf{m L})$} \\
\cline { 2 - 5 } & $\mathbf{6}$ & $\mathbf{1 8}$ & $\mathbf{2 1}$ & FLC \\
\hline C. albicans B3 & $64 / 38.5$ & $64 / 40.0$ & $64 / 42.8$ & 1 \\
C. albicans B4 (MDR1) & $64 / 37.3$ & $64 / 41.2$ & $64 / 43.9$ & 16 \\
C. albicans Gu4 & $32 / 24.2$ & $64 / 36.6$ & $64 / 38.4$ & 4 \\
C. albicans Gu5 (CDR1/CDR2) & $64 / 35.5$ & $64 / 36.2$ & $64 / 39.6$ & 256
\end{tabular}

${ }^{a}$ MICs and $I_{50}$ S were determined by using RPMI-1640 buffered medium, as described in Materials and Methods.

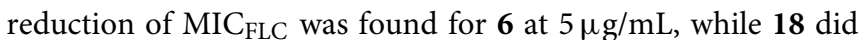
the same at $6.25 \mu \mathrm{g} / \mathrm{mL}$. In the case of C. albicans B4, compounds 21 and 18 caused the twofold reduction of $\mathrm{MIC}_{\mathrm{FLC}}$ at $0.25 \mu \mathrm{g} / \mathrm{mL}$ and $0.1 \mu \mathrm{g} / \mathrm{mL}$, respectively.

Compounds 6, 18, and 21 were also tested for their intrinsic antifungal activity against FLC-resistant and FLC-sensitive $C$. albicans clinical isolates. Comparison of MIC or $\mathrm{IC}_{50}$ values determined for $\mathrm{B} 3 / \mathrm{B} 4$ and $\mathrm{Gu} 4 / \mathrm{Gu} 5$ pairs indicates, how the enhanced activity of a particular transporter affects drug susceptibility. Data presented in Table 4 confirm resistance of B4 and Gu5 strains to FLC. On the other hand, the antifungal activity of chalcones was in most cases not affected by presence/absence of drug transporters, except for the slight effect observed for compound 6 in the case of the Gu4/Gu5 pair, while no difference in MIC values was found for $\mathbf{1 8}$ and 21. These results suggest that $\mathbf{1 8}$ and $\mathbf{2 1}$ are not effluxed by both ABC-type and MFS-type drug transporters of C. albicans, while 6 may be a poor substrate of Cdr1p or Cdr2p but not of Mdrlp.

\section{Effect on ATPase Activity of Cdr1p/Cdr2p}

The effect of selected compounds $(6,21$, and 18) on the ATPase activity of Cdr1p/Cdr2p was studied by determination of the oligomycin-sensitive ATP hydrolysis by plasma membrane preparations isolated from $C$. albicans Gu5 clinical isolate overproducing the $\mathrm{ABC}$ pumps. No significant reduction of the ATPase activity in presence of the tested compounds was found up to $50 \mu \mathrm{g} / \mathrm{mL}$. A very slight reduction, about $20 \%$ was noted for $18(50 \mu \mathrm{g} / \mathrm{mL})$, however at $25 \mu \mathrm{g} / \mathrm{mL}$ the reduction was lower than $5 \%$. It seems therefore that the oxathiolone-fused chalcones studied are not inhibitors of the ATPase activity of the ABC-type C. albicans drug transporters.

\section{Changes in Membrane Potential and Cell Integrity Monitored with the diS- $\mathrm{C}_{3}(3)$ Probe}

Using a set of five isogenic mutant strains, the effect of selected chalcone derivatives on membrane potential and activity of Pdr5p and Snq2p ABC-type drug exporters in S. cerevisiae was tested by the fluorescence method, with $\operatorname{diS}_{-} \mathrm{C}_{3}(3)$ as a probe. Intracellular accumulation of the probe is accompanied by a gradual shift of its $\lambda_{\max }$ toward longer wavelengths (red shift), while any possible efflux results in a blue shift. $\mathrm{DiS}_{-} \mathrm{C}_{3}(3)$ is a substrate for both Pdr5p and Snq2p (Čadek et al., 2004; Hendrych et al., 2009), so that comparison of the probe accumulation curves obtained for Pdr5p- and/or Snq2p-expressing and Pdr5p- and Snq2p-deficient cells measured in the presence of any compound may provide information about its effect on a given drug efflux pump. On the other hand, analysis of the level of staining of pump-deficient cells treated with any compound may reveal its influence on membrane potential, as the blue shift indicates plasma membrane depolarization, while a red shift is usually a consequence of hyperpolarization or permeabilization of the cell membrane. Finally, the cell destruction upon the action of any compound may be confirmed by the consequences of inclusion of the CD cocktail ( $5 \mu \mathrm{M}$ CCCP with $10 \mu \mathrm{M}$ DM-11) into the diS$\mathrm{C}_{3}$ (3) assay. Addition of the lipophilic, weak acid (CCCP) plus the $\mathrm{H}^{+}$-ATPase blocker (DM-11) results in the rapid blue shift for the suspension of intact cells, while the shift does not occur if the cells are broken.

Selected chalcones $\mathbf{6}, \mathbf{1 1}, \mathbf{1 8}$, and $\mathbf{2 1}$ were tested in a broad range of concentrations, from $0.1 \mu \mathrm{M}$ to $20 \mu \mathrm{M}$. The representative staining curves obtained for chalcone derivatives are presented in Figure 1. Cells treated with 11 (Figure 1A) demonstrated the highest initial rate of staining, indicating rapidly increasing cell surface permeability for the probe. It should be noted that the magnitude of the red shift induced by $\mathbf{1 1}$ action on AD1-3 cells (drug efflux pumpfree) was concentration-dependent and was observed even at concentration as low as $0.1 \mu \mathrm{M}$ (graphs not shown). Addition of the CD cocktail caused lower drop of $\lambda_{\max }$, indicating partial cell damage.

Three compounds, 6, 18, and 21, caused hyperpolarization of the cell membrane but did not damage the cells. Increased staining of pump-expressing cells after their exposure to 


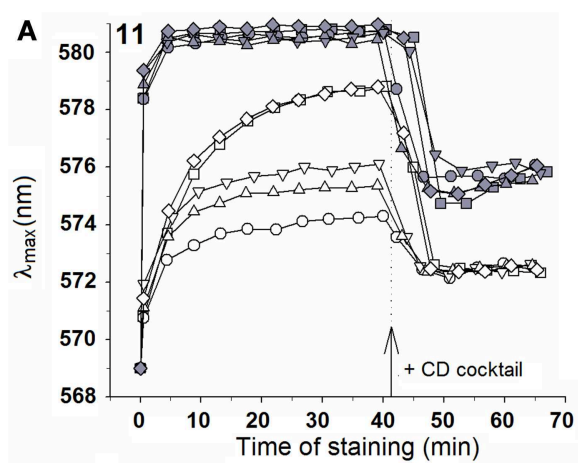

C

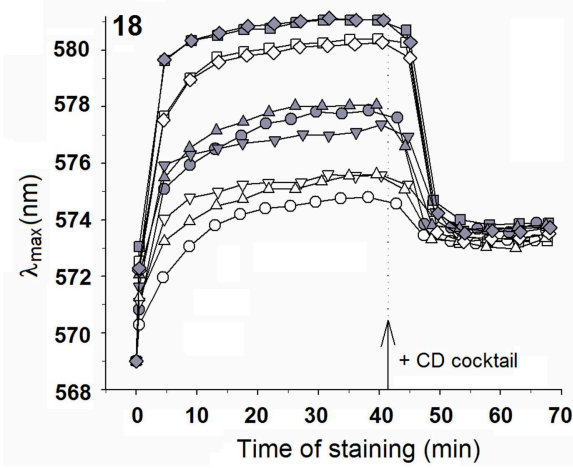

FIGURE 1 | Effect of selected compounds on the membrane potential and activity of MDR pumps of $\mathbf{S}$. cerevisiae. Staining curves of AD1-3 (squares), AD23 (diamonds), AD12 (circles), AD13 (inverted triangles), and US50-18C (triangles) cells. Empty

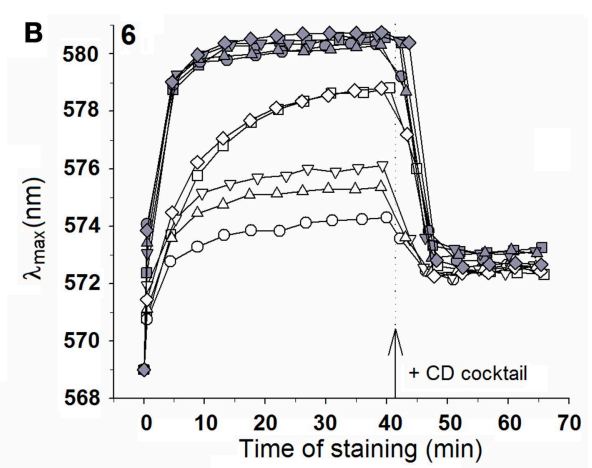

D

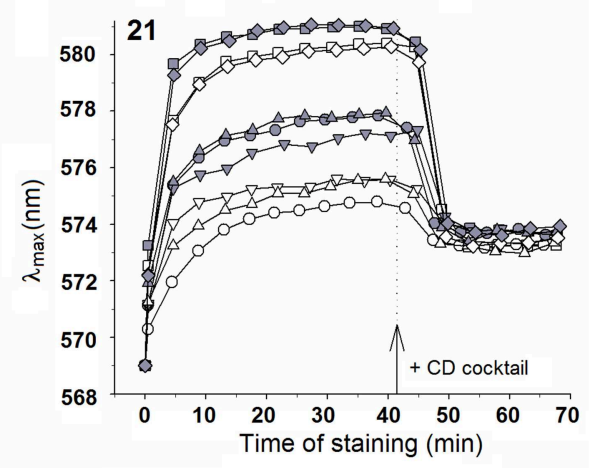

symbols-no compound added; full symbols-compounds added $10 \mathrm{~min}$ before $\mathrm{diS} \mathrm{C}_{3}(3)$ at following concentrations: $1 \mu \mathrm{M}$ (A), $10 \mu \mathrm{M}$ (B-D). Dotted lines with arrows indicate the addition of the CD cocktail. compounds in comparison to chalcone-free controls was caused by both hyperpolarization and inhibition of the probe export. A strong inhibition of $\operatorname{diS}-\mathrm{C}_{3}(3)$ efflux by $\mathbf{6}$ and $\mathbf{1 1}$ was observed in the case of cells expressing Pdr5p or Snq2 (Figures 1A,B), presence of chalcones $\mathbf{1 8}$ and $\mathbf{2 1}$ led only to a partial inhibition of the probe export (Figures 1C,D).

\section{Effect of Chalcone Derivatives on Nile Red Accumulation}

Nile Red (NR) is a fluorogenic substrate of $C$. albicans $\mathrm{ABC}$ transporters Cdr1p and Cdr2p and the MFS transporter Mdr1p (Ivnitski-Steele et al., 2009). The probe was used in a flow cytometry-based assay to measure influence of chalcone derivatives on NR accumulation in yeast cells. Biological models used in these studies were: the Saccharomyces cerevisiae $\mathrm{AD} 1-8 \mathrm{u}^{-}$strain and its fluconazole-resistant transformants: ADCDR1, ADCDR2, and ADMDR1, along with the matched pairs of clinical Candida isolates, F2/F5, Gu4/Gu5, and DSY2039/DSY750. Cells were loaded with NR and levels of fluorescence derived from NR accumulated by chalcone treated pump-expressing cells was compared to that of the pumpdeficient cells. As shown in Figure 2, significantly lower level of NR-derived fluorescence was measured in all resistant cells, comparing to their pump-deficient counterparts, what indicates an active efflux of NR from the former. The ADMDR1 cells accumulated approximately tenfold more, the ADCDR2 cells threefold more and ADCDR1 twofold more of NR in the presence of compound 18 at $70 \mu \mathrm{M}(\sim 28 \mu \mathrm{g} / \mathrm{mL})$ than the AD1$8 \mathrm{u}^{-}$cells. Significant accumulation NR in ADMDR1 was also induced by 21. Accumulation of NR in ADCDR1 and ADCDR2 cells remained unaffected by 11. Further studies showed that 21 and 18 at concentrations as low as $0.5 \mu \mathrm{g} / \mathrm{mL}$ still strongly inhibited NR efflux from ADMDR1, causing a twofold higher

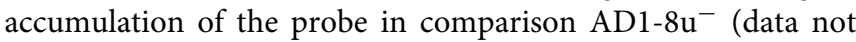
shown). Compound $\mathbf{6}$ at $70 \mu \mathrm{M}$ caused significant accumulation of NR exclusively in ADCDR2 and ADCDR1 $(2.5 \times$ and $2 \times$, respectively in comparison to $\mathrm{AD} 1-8 \mathrm{u}^{-}$), with no effect on ADMDR1 (details not shown).

The inhibitory effect of $\mathbf{2 1}$ and $\mathbf{1 8}$ on MDR1p-mediated efflux was confirmed in the model of clinical Candida isolates. Compound 21 inhibited NR efflux only from the cells of the F5 and DSY750 strains overexpressing the MDR1 gene, where respectively fivefold and twofold increase in NR-derived fluorescence was observed. Surprisingly enough, compound $\mathbf{1 8}$ was also found to interfere only with Mdr1p-mediated efflux. In F5 cells, accumulation of NR increased two times and in DSY750, three times. Both compounds were not able to inhibit NR efflux from Gu5 isolate overproducing Cdr1p and Cdr2p proteins. Some accumulation of NR in Gu5 but not in F5 and DS750 was observed in the presence of $\mathbf{6}$ (details not shown). 


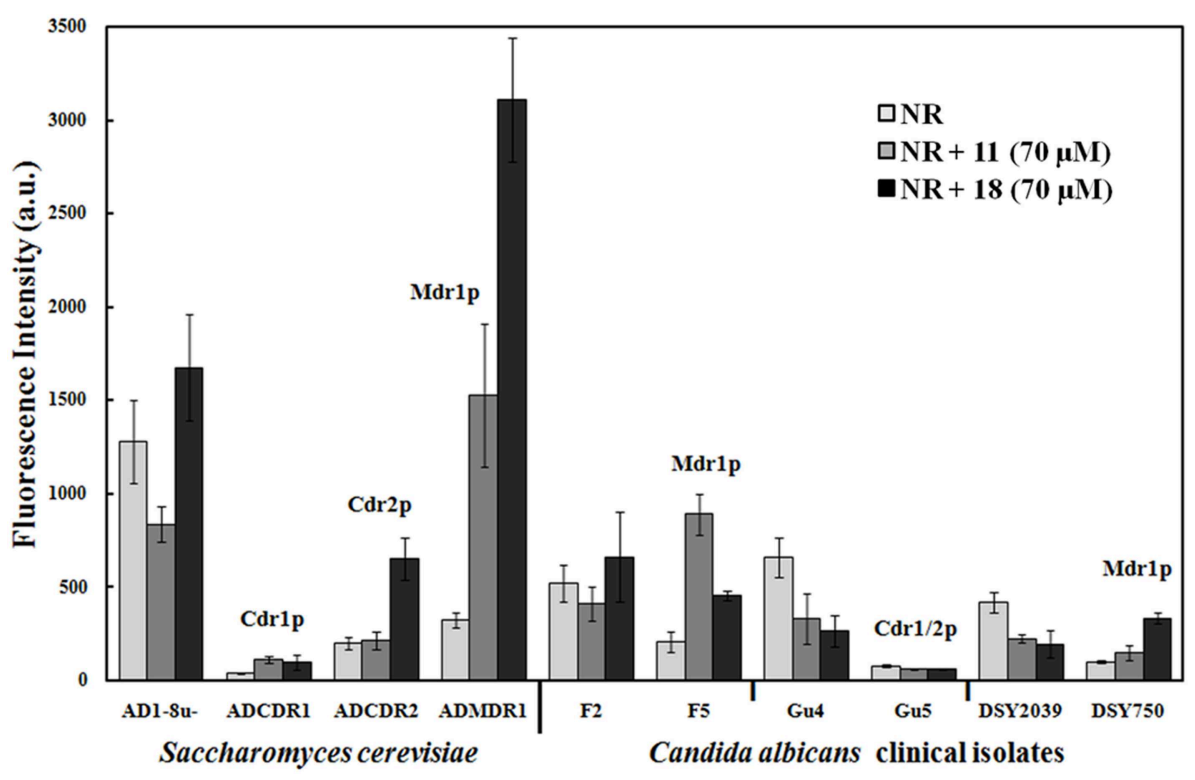

FIGURE 2 | Influence of selected chalcones on Nile Red accumulation in drug efflux pump-free and MDR yeast cells. Cells were incubated for 30 min with Nile Red and chalcones and then fluorescence was measured with a flow cytometer. Values are the means of three independent experiments. Bars represent SD.

Interestingly, in all sensitive strains, presence of $\mathbf{2 1}$ resulted in lower NR accumulation than presence of $\mathbf{1 8 .}$

\section{Effect of Chalcones on Rhodamine 6G Efflux}

In order to get more data characterizing chalcone derivatives as substrates of membrane multidrug transporters, their effect on efflux from yeast cells of another probe, Rhodamine 6G (R6G), which is a known substrate of Cdr1p/Cdr2p but not of the Mdrlp transporter, was investigated. Saccharomyces

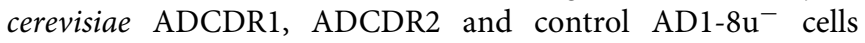
were first de-energized in presence of 2-deoxy-D-glucose and 2,4-dinitrophenol, then loaded with R6G (final concentration $10 \mu \mathrm{M}$ ) along with a compound tested and subsequently activity of drug-effluxing ABC-type proteins was triggered by glucose addition. Concentration of the effluxed R6G was determined after $30 \mathrm{~min}$ in supernatants obtained after cell harvesting.

The ADCDR1 and ADCDR2 cells extruded five times more R6G than the AD1-8u ${ }^{-}$cells, thus confirming that this compound is indeed a substrate of the Cdr1p and Cdr2p drug transporters. Presence of compounds 6, 18, and 21 at $100 \mu \mathrm{M}$ $(\sim 40 \mu \mathrm{g} / \mathrm{mL})$ did not change the amount of R6G released from $\mathrm{AD} 1-8 \mathrm{u}^{-}$cells. Addition of 21 at $100 \mu \mathrm{M}$ to the suspension of ADCDR1 or ADCDR2 cells inhibited R6G efflux only in about $5 \pm 9 \%$ and $8 \pm 4 \%$, respectively, whereas presence of $\mathbf{6}$ and $\mathbf{1 8}$ at the same concentration resulted in $45 \pm 10 \%$ and $38 \pm 9 \%$ inhibition of the probe efflux from ADCDR2 and in $27 \pm 8 \%$ and $33 \pm 6 \%$ inhibition of R6G export from ADCDR1, compared to the untreated cells. These results corresponded well with those from the Nile Red assay and showed that compounds $\mathbf{6}$ and 18 may block to some extent the Cdr1p/Cdr2p-mediated efflux from recombinant $S$. cerevisiae, while presence of $\mathbf{2 1}$ had almost no effect on the activity of this drug transporter.

\section{Influence of Chalcones on Cell Wall Structure}

The effect of selected chalcones on morphology and ultrastructure of $C$. albicans cells was investigated using transmission electron microscopy (TEM). The morphological alterations observed in cells treated with 6, 11, 18, or 21 at $10 \mu \mathrm{g} / \mathrm{mL}$ were documented by microphotographs and some of these photos are shown in Figure 3. The cross-section of untreated cells reveals a typical morphology with an intact cell wall and cytoplasmic membrane, separated by a low-density space (Figure 3A). Treatment of cells with compounds 6, 18, and 21 did not cause any visible changes, as the crosssections of chalcone-treated cells looked very similar to those of the untreated control (photos not shown). This is not surprising, since $10 \mu \mathrm{g} / \mathrm{mL}$ is well below the MIC value of these compounds $(64 \mu \mathrm{g} / \mathrm{mL})$. On the other hand, 11 induced significant morphological changes, which ranged from some discrete alterations to the total destruction of the outer layers of fungal cells (Figures 3B-D). A common alteration observed after treatment with compound $\mathbf{1 1}$ was a loss of a typical layered structure and discontinuity or even disappearance of the cytoplasmic membrane (Figures 3C,D). Other changes comprised appearance of the irregular cell surfaces, loss of cell-wall integrity and penetrating lesions of the wall with an apparent shedding of the cell components (Figure 3C).

\section{Discussion}

Three out of 27 chalcones studied in this work (Figure 4) appeared effective chemosensitizers, able to restore to large extent sensitivity to fluconazole of MDR C. albicans strains. Compound 21 effectively chemosensitized cells overexpressing the MFS-type Mdrlp, compound 6 did the same with cells 


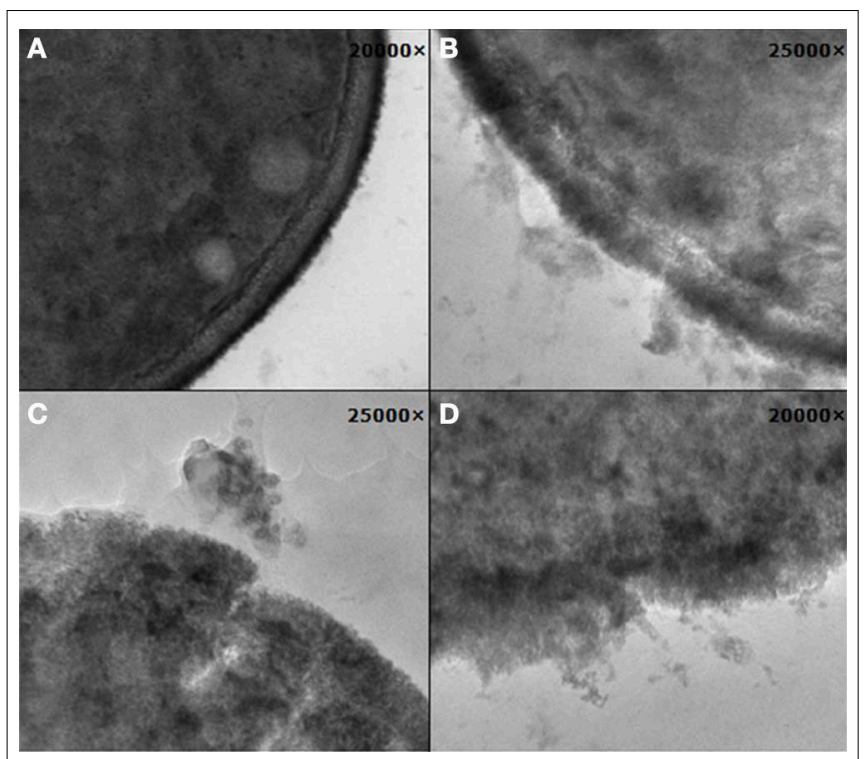

FIGURE 3 | Changes in the cell surface of $C$. albicans cells observed by transmission electron microscopy: (A) control cells; (B-D) cells treated with $11,10 \mu \mathrm{g} / \mathrm{mL}$, for 3,6 , and $9 \mathrm{~h}$.

FLC-resistant due to the activity of ABC-type drug transporters and derivative 18 partially reversed fluconazole resistance mediated by both types of yeast drug efflux pumps. This is worth mentioning that compounds $\mathbf{6}, \mathbf{1 8}$, and 21 demonstrated low in vitro mammalian toxicity against different cell lines in the tissue cultures (Konieczny et al., 2007a,b,c), what makes them promising candidates for clinical application as agents augmenting antifungal chemotherapy with FLC of infections caused by MDR C. albicans. On the other hand, the chemosensitizing potential of $\mathbf{1 1}$ seems questionable, since this compound exhibits a strong growth inhibitory and fungicidal effect at relatively low concentrations. In our previous studies we provided evidence for inhibition of chitin biosynthesis as a molecular basis of fungistatic effect of $\mathbf{1 1}$ and for inhibition of $\beta(1 \rightarrow 3)$ glucan synthase resulting in fungicidal action of this chalcone derivative (Łạcka et al., 2011). The latter has been now confirmed by the loss of continuity of $C$. albicans cells and the appearance of the cell wall defects, followed by leakage of cell components, demonstrated by TEM upon the action of 11 at concentration well above its MIC and close to the MFC value. Destruction of $S$. cerevisiae cells treated with 11, revealed by the results of experiments involving the $\mathrm{diS}-\mathrm{C}_{3}(3)$ fluorescent probe, provides another evidence confirming this hypothesis. Inhibition of chitin biosynthesis by $\mathbf{1 1}$ at concentrations close to its MIC (Eạcka et al., 2011) seems to constitute a molecular basis for the observed synergism of $\mathbf{1 1}$ and FLC, similarly as it was shown previously for combination of the known inhibitor of chitin synthase nikkomycin and azole antifungals (Milewski et al., 1991).

It is not clear why the chemosensitizing potency of $\mathbf{6}, \mathbf{1 8}$, and $\mathbf{2 1}$ is much better than that of their other close structural analogs tested by us. The only characteristic common structural pattern observed here is presence of the $4^{\prime}$-dimethylaminoalkoxy

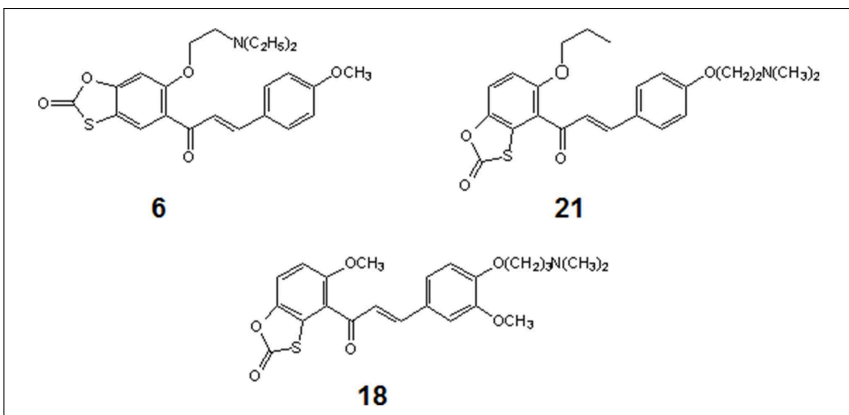

FIGURE 4 | Structures of chemosensitizers of MDR yeasts selected in this study.

substituent in ring B (compounds 11, 16, 18, and 21) that seems beneficial for the chemosensitizing efficacy (18 and 21) or high antifungal activity (11) of type 2 oxathiolone fused chalcones but this effect is abolished when the similar substituent is also present in the A ring (16).

Results of experiments employing Rhodamine $6 \mathrm{G}$ and Nile Red showed that some chalcones studied effectively interfered with extrusion of the fluorescent probes by the ABC and/or MFS proteins. Compounds 18 and $\mathbf{6}$ inhibited the efflux of Nile Red by Cdr1p, Cdr2p, and Mdr1p, export of Rhodamine $6 \mathrm{G}$ by the Cdr1p and Cdr2p transporters and efflux of diS$\mathrm{C}_{3}$ (3) from the $S$. cerevisiae strain overexpressing PDR5. On the other hand, 21 did not affect the Rhodamine 6G and Nile Red efflux mediated by Cdr1p/Cdr2p efflux and poorly affected export of $\mathrm{diS}_{-} \mathrm{C}_{3}(3)$ from $S$. cerevisiae strains overexpressing PDR5 and/or SNQ2, while it effectively inhibited the efflux of Nile Red from strains overexpressing MDR1. An inhibitory effect of 6 on Pdr5p- and Snq2p-mediated efflux of the diS$\mathrm{C}_{3}(3)$ probe and a very slight inhibition of the Cdr1p/Cdr2pderived ATPase activity under in vitro conditions indicates its possible inhibitory activity against different ABC-type yeast drug transporters, probably not resulting from interaction with the ATP-binding domains. Previously it was shown that 4alkoxychalcones (structure different from that of compounds described in this study) bind to the ATP binding site and to the steroid binding site of mammalian ABC-type drug transporter P-glycoprote (Conseil et al., 1998). It is possible therefore that compound $\mathbf{6}$ may also bind to more than one site in the ABC-type yeast drug transporters.

The fact that some chalcones effectively prevented extrusion of particular fluorescent probes from MDR C. albicans cells and chemosensitized MDR cells to FLC but on the other hand, their intrinsic anticandidal activity against FLC-resistant MDR cells, was very similar or the same as against FLC-sensitive cells, may indicate that these compounds bind to the MDR proteins outside their substrate-binding sites and prevent binding of probes or fluconazole to these sites but are not effectively extruded by the drug efflux pumps. In summary, the observed effect of sensitization of resistant strains of Candida albicans to FLC in the presence of chalconic chemosensitizers, most likely results from a non-competitive inhibition of drug efflux proteins, especially those of the MFS-type, although this hypothesis should be further verified. 


\section{Acknowledgments}

The authors are grateful to Joachim Morschhäuser, Dominique Sanglard and Andre Goffeau for the generous gifts of C. albicans

\section{References}

Balzi, E., Chen, W., Ulaszewski, S., Capieaux, E., and Goffeau, A. (1987). The multidrug resistance gene PDR1 from Saccharomyces cerevisiae. J. Biol. Chem. 262, 16871-16879.

Čadek, R., Chládková, K., Sigler, K., and Gášková, D. (2004). Impact of the growth phase on the activity of multidrug resistance pumps and membrane potential of S. cerevisiae: effect of pump overproduction and carbon source. Biochim. Biophys. Acta 1665, 111-117. doi: 10.1016/j.bbamem.2004.06.020

Clinical Laboratory Standards Institute. (2008). Reference Method for Broth Dilution Antifungal Susceptibility Testing of Yeasts-Second Edition. Approved Standard M27-A3. Wayne, PA: CLSI.

Conseil, G., Baubichon-Cortay, H., Dayan, G., Jault, J. M., Barron, D., and Di Pietro, A. (1998). Flavonoids: a class of modulators with bifunctional interactions at vicinal ATP- and steroid-binding sites on mouse P-glycoprotein. Proc. Natl. Acad. Sci. U.S.A. 95, 9831-9836. doi: 10.1073/pnas.95.17.9831

Conseil, G., Decottignies, A., Jault, J. M., Comte, G., Barron, D., Goffeau, A., et al. (2000). Prenyl-flavonoids as potent inhibitors of the Pdr5p multidrug ABC transporter from Saccharomyces cerevisiae. Biochemistry 39, 6910-6917. doi: 10.1021/bi000040f

Decottignies, A., Grant, A. M., Nichols, J. W., de Wet, H., McIntosh, D. B., and Goffeau, A. (1998). ATP-ase and multidrug transport activities of overexpressed yeast ABC protein Yor1p. J. Biol. Chem. 273, 12612-12622. doi: 10.1074/jbc.273.20.12612

Dimmock, J. R., Elias, D. W., Beazely, M. A., and Kandepu, N. M. (1999). Bioactivities of chalcones. Curr. Med. Chem. 6, 1125-1149.

Diwischek, F., Morschhäuser, J., and Holzgrabe, U. (2009). Cerulenin analogues as inhibitors of efflux pumps in drug-resistant Candida albicans. Arch. Pharm. (Weinheim) 342, 150-164. doi: 10.1002/ardp.200800160

Franz, R., Kelly, S. L., Lamb, D. C., Kelly, D. E., Ruhnke, M., and Morschhäuser, J. (1998). Multiple molecular mechanisms contribute to a stepwise development of fluconazole resistance in clinical Candida albicans strains. Antimicrob. Agents Chemother. 42, 3065-3072.

Franz, R., Ruhnke, M., and Morschhäuser, J. (1999). Molecular aspects of fluconazole resistance development in Candida albicans. Mycoses 42, 453-458. doi: 10.1046/j.1439-0507.1999.00498.x

Gupta, V., Kohli, A., Krishnamurthy, S., Puri, N., Aalamgeer, S. A., Panwar, S., et al. (1998). Identification of polymorphic mutant alleles of CaMDR1, a major facilitator of $C$. albicans which confers multidrug resistance and its in vitro transcriptional activation. Curr. Genet. 34, 192-199. doi: 10.1007/s002940050385

Hendrych, T., Kodedová, M., Sigler, K., and Gášková, D. (2009). Characterization of the kinetics and mechanisms of inhibition of drugs interacting with the $S$. cerevisiae multidrug resistance pumps Pdr5p and Snq2p. Biochim. Biophys. Acta 1788, 717-723. doi: 10.1016/j.bbamem.2008.12.001

Holmes, A. R., Keniya, M. V., Ivnitski-Steele, I., Monk, B. C., Lamping, E., Sklar, L. A., et al. (2012). The monoamine oxidase A inhibitor clorgyline is a broad-spectrum inhibitor of fungal ABC and MFS transporter efflux pump activities which reverses the azole resistance of Candida albicans and Candida glabrata clinical isolates. Antimicrob. Agents Chemother. 56, 1508-1515. doi: 10.1128/AAC.05706-11

Ivanova, A., Batovska, D., Engi, H., Parushev, S., Ocsovszki, I., Kostova, I., et al. (2008). MDR-reversal activity of chalcones. In Vivo 22, 379-384.

Ivnitski-Steele, I., Holmes, A. R., Lamping, E., Monk, B. C., Cannon, R. D., and Sklar, L. A. (2009). Identification of Nile red as a fluorescent substrate of the Candida albicans ATP-binding cassette transporters Cdr1p and Cdr2p and the major facilitator superfamily transporter Mdr1p. Anal. Biochem. 394, 87-91. doi: 10.1016/j.ab.2009.07.001

Keniya, M. V., Fleischer, E., Klinger, A., Cannon, R. D., and Monk, B. C. (2015). Inhibitors of the Candida albicans Major Facilitator Superfamily transporter clinical isolates and S. cerevisiae strains. Financial support to this study was provided by the Polish Ministry for Science and Higher Education grant. The work was also supported by the Czech Science Foundation grant 205/10/1121.
Mdr1p responsible for fluconazole resistance. PLoS ONE 10:e0126350. doi: 10.1371/journal.pone.0126350

Konieczny, M. T., Konieczny, W., Pirska, D., Bułakowska, A., Sabisz, M., Składanowski, A., et al. (2007a). Synthesis of oxathiolone fused chalcones bearing O-aminoalkyl side chain. Comparison of stability of isomeric benzoxathiolones under alkylation reaction conditions. Heterocycles 71, 2595-2615. doi: 10.3987/COM-07-11165

Konieczny, M. T., Konieczny, W., Sabisz, M., Składanowski, A., Wakieć, R., Augustynowicz-Kopeć, E., et al. (2007b). Acid-catalyzed synthesis of oxathiolone fused chalcones. Comparison of their activity toward various microorganisms and human cancer cells line. Eur. J. Med. Chem. 42, 729-733. doi: 10.1016/j.ejmech.2006.12.014

Konieczny, M. T., Konieczny, W., Sabisz, M., Składanowski, A., Wakieć, R., Augustynowicz-Kopeć, E., et al. (2007c). Synthesis of isomeric, oxathiolone fused chalcones and comparison of their activity toward various microorganisms and human cancer cells line. Chem. Pharm. Bull. 55, 817-820. doi: $10.1248 / \mathrm{cpb} .55 .817$

Łącka , I., Konieczny, M. T., Bułakowska, A., Rzymowski, T., and Milewski, S. (2011). Antifungal action of the oxathiolone fused chalcone derivative. Mycoses 54, e407-e414. doi: 10.1111/j.1439-0507.2010.01936.x

Liu, X. L., Tee, H. W., and Go, M. L. (2008). Functionalized chalcones as selective inhibitors of P-glycoprotein and breast cancer resistance protein. Bioorg. Med. Chem. 16, 171-180. doi: 10.1016/j.bmc.2007.10.006

López, S. N., Castelli, M. V., Zacchino, S. A., Domiìnguez, J. N., Lobo, G., CharrisCharris, J. et al. (2001). In vitro antifungal evaluation and structure-activity relationships of a new series of chalcone derivatives and synthetic analogues, with inhibitory properties against polymers of the fungal cell wall. Bioorg. Med. Chem. 9, 1999-2013. doi: 10.1016/S0968-0896(01)00116-X

Marchetti, O., Moreillon, P., Glauser, M. P., Bille, J., and Sanglard, D. (2000). Potent synergism of the combination of fluconazole and cyclosporine in Candida albicans. Antimicrob. Agents Chemother. 44, 2373-2381. doi: 10.1128/AAC.44.9.2373-2381.2000

Milewski, S., Mignini, F., and Borowski, E. (1991). Synergistic action of nikkomycin X/Z with azole antifungals on Candida albicans. J. Gen. Microbiol. 137, 2155-2161 doi: 10.1099/00221287-137-9-2155

Nowakowska, Z. (2007). A review of anti-infective and anti-inflammatory chalcones. Eur. J. Med. Chem. 42, 125-137. doi: 10.1016/j.ejmech.2006. 09.019

Odds, F. C. (2003). Synergy, antagonism, and what the chequerboard puts between them. J. Antimicrob. Chemother. 52, 1. doi: 10.1093/jac/dkg301

Pfaller, M. A., and Diekema, D. J. (2007). Epidemiology of invasive candidiasis: a persistent public health problem. Clin. Microbiol. Rev. 20, 133-163. doi: 10.1128/CMR.00029-06

Pfaller, M. A. (2012). Antifungal drug resistance: mechanisms, epidemiology, and consequences for treatment. Am. J. Med. 125, S3-S13. doi: 10.1016/j.amjmed.2011.11.001

Prasad, R., De Wergifosse, P., and Goffeau, A. (1998). Molecular cloning and characterization of a novel gene of Candida albicans, CDR1 conferring multiple resistance to drugs and antifungals. Curr. Genet. 27, 320-329. doi: 10.1007/BF00352101

Prasad, R., and Goffeau, A. (2012). Yeast ATP-binding cassette transporters conferring multidrug resistance. Ann. Rev. Microbiol. 66, 37-61. doi: 10.1146/annurev-micro-092611-150111

Prasad, R., Panwar, S. L., and Smriti, (2002). Drug resistance in yeasts - an emerging scenario. Adv. Microb. Physiol. 46, 155-201. doi: 10.1016/S00652911(02)46004-3

Ricardo, E., Costa-de-Oliveira, S., Dias, A. S., Guerra, J., Rodrigues, A. G., and Pina-Vaz, C. (2009). Ibuprofen reverts antifungal resistance on Candida albicans showing overexpression of CDR genes. FEMS Yeast Res. 9, 618-625. doi: $10.1111 / j .1567-1364.2009 .00504 . x$ 
Sanglard, D., and Odds, F. C. (2002). Resistance of Candida species to antifungal agents: molecular mechanisms and clinical consequences. Lancet Infect. Dis. 2, 73-85. doi: 10.1016/S1473-3099(02)00181-0

Sharma, A., Chakravarti, B., Gupta, M. P., Siddiqui, J. A., Konwar, R., and Tripathi, R. P. (2010). Synthesis and anti breast cancer activity of biphenyl based chalcones. Bioorg. Med. Chem. 18, 4711-4720. doi: 10.1016/j.bmc.2010.05.015

Sharma, M., Manoharlal, R., Shukla, S., Puri, N., Prasad, T., Ambudkar, S. V., et al. (2009). Curcumin modulated efflux mediated by yeast ABC multidrug transporters and is synergistic with antifungals. Antimicrob. Agents Chemother. 53, 3256-3265. doi: 10.1128/AAC.01497-08

Smriti, Krishnamurthy, S., Dixit, B. L., Gupta, C. M., Milewski, S., and Prasad, R. (2002). ABC transporters Cdr1p, Cdr2p and Cdr3p of a human pathogen Candida albicans are general phospholipid translocators. Yeast 19, 303-318. doi: $10.1002 /$ yea.818

Srinivasan, A., Lopez-Ribot, J. L., and Ramasubramanian, A. K. (2012). Overcoming antifungal resistance. Drug Discov. Today Technol. 11, 65-71. doi: 10.1016/j.ddtec.2014.02.005
Wink, M., Ashour, M. L., and Zaki El-Readi, M. (2012). Secondary metabolites from plants inhibiting $\mathrm{ABC}$ transporters and reversing resistance of cancer cells and microbes to cytotoxic and antimicrobial agents. Front. Microbiol. 3:130. doi: 10.3389/fmicb.2012. 00130

Conflict of Interest Statement: The authors declare that the research was conducted in the absence of any commercial or financial relationships that could be construed as a potential conflict of interest.

Copyright (c) 2015 Łacka, Konieczny, Bułakowska, Kodedová, Gašková, Maurya, Prasad and Milewski. This is an open-access article distributed under the terms of the Creative Commons Attribution License (CC BY). The use, distribution or reproduction in other forums is permitted, provided the original author (s) or licensor are credited and that the original publication in this journal is cited, in accordance with accepted academic practice. No use, distribution or reproduction is permitted which does not comply with these terms. 